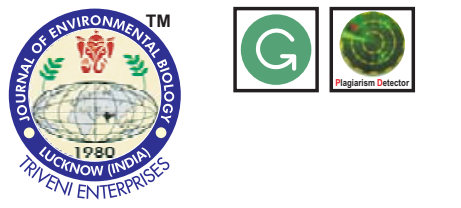

DOI : http://doi.org/10.22438/jeb/38/6/MRN-433

\title{
Genetic purity assessment of indica rice hybrids through DNA fingerprinting and grow out test
}

Authors Info

R.L. Verma ${ }^{1 *}$, S. Singh ${ }^{2}$, P. Singh ${ }^{3}$, V. Kumar', S.P. Singh', S. Singh", S. Samantaray' and O.N. Singh ${ }^{1}$ 'Division of Crop Improvement, Indian Council of Agriculture Research-National Rice Research Institute, Cuttack-753 006, India

${ }^{2}$ Department of Genetics and Plant Breeding, College of Agriculture, G. B. Pant University of Agriculture and Technology, Pantnagar-263 145, India

${ }^{3}$ Department of Plant Breeding and Genetics, Veer Kunwar Singh College of Agriculture, Dumraon (Bihar Agricultural University, Sabour), Buxar-802 136, India

${ }^{4}$ Department of Agricultural Botany, Udai Pratap Autonomous College, Varanasi-221 002, India

${ }^{*}$ Corresponding Author Email : ram.pantvarsity@gmail.com

Key words

DNA fingerprinting

Genetic purity

Grow out test

Indica rice hybrids

Microsatellite markers

Publication Info

Paper received : 13.08 .2016

Revised received : 09.02.2017

Re-revised received : 20.02.2017

Accepted : 23.03.2017

\begin{abstract}
Aim : Varietal identity and their purity assessment is essential to assert intellectual rights to breeder, helps seed testing and certification agencies to ensure pure seeds to the farmers, buyers, processors and consumers.

Methodology : In the present study, molecular characterization and genetic purity analysis of nine indica rice hybrids and respective 13 parental lines (22 genotypes) were done utilizing grow out test grow out test and micro-satellite markers based DNA fingerprinting approach. A total of 48 microsatellite (SSR and STMS) markers spanning over whole rice genome were screened.
\end{abstract}

Results : The statistical analysis of grow out test revealed that 88.25 per cent genetic purity was assessed in 3 hybrids tested. Twelve out of 48 microsatellite used were found polymorphic and amplified a total of 29 alleles among the genotypes with an average polymorphic information content value of 0.45 . Out of 12 informative markers, nine were found polymorphic across the genotypes and produced unique fingerprints. Five STMS markers (RM154, RM164, RM234, RM258 and RM519) showed polymorphism over all the genotypes and were identified as referral marker for use in unambiguous identification and protection of nine hybrids. Nevertheless, marker RM 19 amplified allele was specific to the parental lines of $\mathrm{CNRH} 3$ and APHR 2 (having common CMS line, IR62829). The results on genetic purity test through GOT had highly significant positive correlation $(r=0.96)$ with molecular marker analysis.

Interpretation : Genotype specific STMS markers identified in the study and their close association with the ability of grow out test, emphasizes immense scope for molecular approaches to be an alternatives in unambiguous assessment of genetic purity of hybrids and their parents. The molecular markers based genetic purity assessment may serve as a probable substitute to grow out test, which is a cumbersome and time consuming task and would benefit the farmers and agencies involved in this venture, hybrid rice seed production and cultivation.

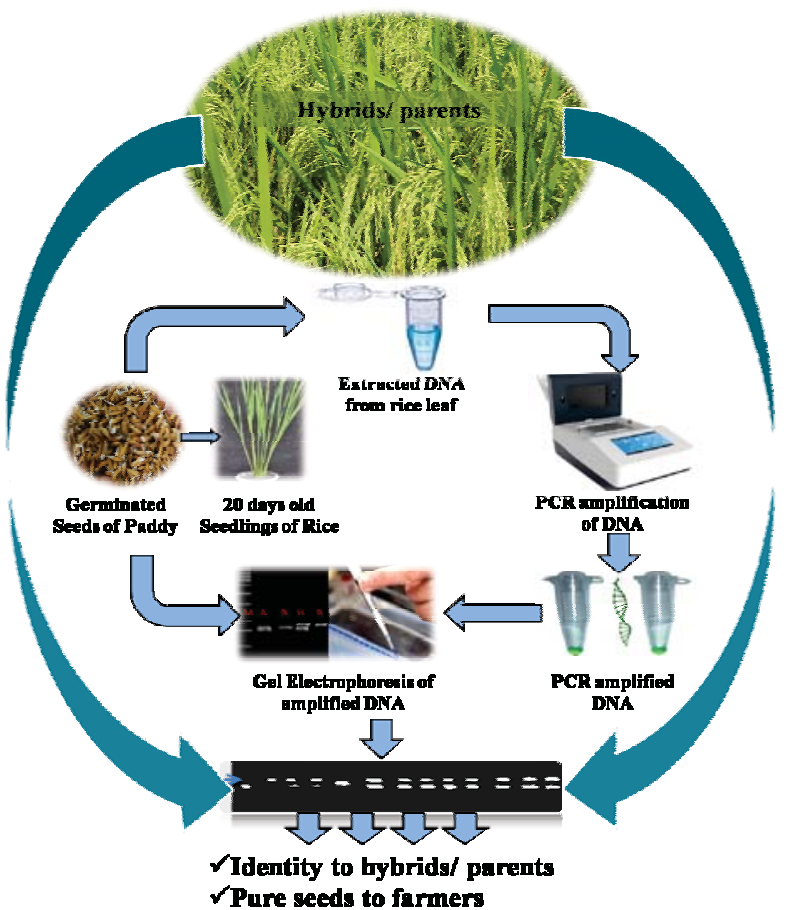




\section{Introduction}

Rice (Oryza sativa) is a staple food crop of global significance used as a primary food by more than half of the world's population (Singh et al., 2013). It is a premier crop, in terms of its calorie contribution to human diet and monetary value of food production in developing world (Sasaki, 2005; Singh et al., 2014). Globally, it occupies more than 146 million ha land which produces approximately 685 million tonnes of grain annually (RMM-USDA, 2015). It has great role in alleviating poverty and malnutrition, and reaffirming the need to focus world attention on its role in providing food security and eradicating poverty, especially in developing countries (IRRI, 2015). In India, rice occupies about 44 million ha of cultivatable area ( $22 \%$ of total cropped area) with an annual production of 106.54 million tonnes, which contributes approximately $25 \%$ to agricultural GDP.

In Asian countries, most of the cultivable land suitable for rice production has already been exploited. The world population is expected to reach upto 8.2 billion with the global demand of approximate 533 million tonnes of milled rice by the end of year 2030 as compared to 477 million tons projected for 2015 (IRRI, 2015; RMM-USDA, 2015). In this scenario, hybrid rice technology is considered as a viable option to increase rice yield globally as it gives on an average about 20 - $25 \%$ higher yield than the conventional high yielding varieties (Virmani, 1994; Kumar et al., 2012). However, the unavailability of pure seed of hybrids at the affordable cost and lack of specific resistance to some major biotic and abiotic stresses are the major constraints in large scale adoption of the technology.

The ability to assess varietal identity and purity not only helps the plant breeder to assert breeders rights, but also benefits the variety and seed testing authorities, the certification agencies, farmers and buyers, processors and consumers. According to Mao et al. (1998) and Kumar et al. (2012) every one percent of impurity in hybrid seeds could reduce the yield upto $100 \mathrm{~kg}$ per $\mathrm{ha}^{-1}$. The area of the most concern for the future hybrid rice programme is the long-term maintenance of the genetic purity of the hybrid, parental lines ( $A, B$ and $R$ lines) and also maintenance of high level of genetic purity in hybrids is essential to exploit the moderate level of heterosis observed in crop (Yashitola et al., 2002; Nandkumar et al., 2004). Thus, there is a need to assess the genetic purity of hybrid seeds in quick succession so that seeds produced in dry season could reach the farmers for commercial cultivation in very next wet season.

The purity of hybrid seeds is conventionally assayed by conducting grow out test involving representative sample of the seeds to be marketed (Bora et al., 2016). Grow-out test generally based on some highly heritable traits "descriptors" requires one full season to complete, hence, it is tedious and time taking and highly input extensive. Molecular markers, in contrast, offer an impartial means for precise molecular profiling of varieties/hybrids and their purity assessment in short span of time (Rehem et al., 2010). Microsatellite (SSR/ STMS) marker based high level of polymorphism or fingerprinting assays have now emerged as one of the new and rapid technology for cultivar/ impurity identification to replace/ supplement the conventional grow-out test grow out test (Yashitola et al., 2002; Yifru et al., 2006; Lu et al., 2009; Bora et al., 2016). Cytoplasmic male sterile (CMS-A line), maintainer (B-line), restorer (R-line) lines and their hybrids have been screened by a number of microsatellite and sequence tagged site markers by several workers (Sundaram et al., 2008 ; Jaikishan et al., 2010; Kumar et al., 2012, 2016; Dash et al., 2016).

Therefore, keeping in view of the above facts, the objective of the present study was to estimate and identify the level of purity in seed lots of nine rice hybrids with their parental lines through microsatellite markers based DNA fingerprints and grow out test, and also to establish the basis for identification, authentication, protection and monitoring of seed purity for hybrids evaluated.

\section{Materials and Methods}

Experimental materials and practices : Geographically, the experimental site is situated at $29^{\circ} \mathrm{N}$ latitude and $79.3^{\circ}$ E longitude at an altitude of $243.8 \mathrm{~m}$ above the mean sea level and in the foothills of Shivalik range of the Himalayas in narrow belt called Terai. Further, laboratory work was carried out in Rice Research Laboratory, Department of Genetics and Plant Breeding, G. B. Pant University of Agriculture and Technology, Pantnagar, Uttarakhand, India and Biotechnology Laboratory, Division of Crop Improvement, National Rice Research Institute, Cuttack, Odisha, India during 2013-14. The experimental materials used in this study comprised nine indica rice hybrids (Pant Sankar Dhan1, Pant Sankar Dhan 3, Narendra Sankar Dhan 2, KRH-2, CORH2, DRRH-1, Sahyadri, CNRH 3 and APHR-2) and thirteen parental lines including two CMS (A) lines with their maintainer (B) lines (IR 58025A and B, IR 62829A and B) and nine restorer (R) lines (UPRI 92-133R, UPRI 93-287R, NDR 30264R, MTU3026R, KMR-3R, C-20R, BR-827-35R, IR-407050R and Ajaya). These nine hybrids are well adapted to different climatic zones with good yield potential. The seeds were obtained from different institutions/agencies in the country.

Twenty-two lines were sown on well prepared seed-bed (Terai) to raise the seedlings during Kharif season (June to November) of 2010-2012. Twenty-one days old single seedlings were transplanted in randomized block design under three replications in separate plots $\left(15 \mathrm{~m}^{2}\right)$ of 3 meter length with $25 \times 20$ cm spacing. The fertilizers were applied @ $140 \mathrm{~kg} \mathrm{~N}, 80 \mathrm{~kg} \mathrm{P}_{2} \mathrm{O}_{5}$, and $60 \mathrm{~kg} \mathrm{~K}_{2} \mathrm{O}$ per hectare (as per recommendation of hybrid rice cultivation). Half of the $\mathrm{N}_{2}$ and full dose of $\mathrm{P}_{2} \mathrm{O}_{5}$ and $\mathrm{K}_{2} \mathrm{O}$ were used as basal dose. Remaining half of nitrogen was applied at the time of tillering. The experimental field was kept free from weeds by 
adopting manual weeding and herbicide application. All the recommended cultural practices and plant protection measures were followed to raise the healthy crop. Laboratory work was carried out in Rice Research Laboratory, G. B. Pant University of Agriculture and Technology, Pantnagar, and Biotechnology Laboratory, National Rice Research Institute, Cuttack, during 2013-14.

Grow out test : Grow out test is used to determine the genuineness (true to the type) of variety/ hybrid and it is based on the morphological traits of variety/ hybrids which are highly suitable, easily categorized by naked eye and least influenced by the environment. For grow out test, thirteen morphological characters taken from DUS (distinguish uniformity stability) test viz., basal stem colour, leaf colour intensity, early flowering, late flowering, male sterility, stem length excluding panicles, altitude of blade in flag leaf, curvature of main axis of panicle, panicles awn, branching altitude of panicle, panicle exertion and time of maturity. These 13 observations were taken under investigation from eight selected lines viz., 3 hybrids (Pant Sankar Dhan 1, Pant Sankar Dhan 3 and Narendra Sankar Dhan 2) and one CMS line (UPRI 95-17 :Aline), one maintainer line (UPRI 95-17 : B line) and 3 restorers (UPRI 92-133, UPRI 93-287 and NDR 30264 : R lines) of hybrids. The observations were recorded from randomly selected more than 200 plants in field plot and subjected to statistical analysis for correlation with molecular data.

Molecular marker based genetic purity analysis : Genomic DNA of each plant was isolated from fresh leaf ( $100 \mathrm{mg}$ each) samples (18 days old seedlings) using cetyl trimethyl ammonium bromide (CTAB) method following the protocol of Murray and Thompson (1980). DNA concentration was then analyzed by taking $\mathrm{OD}_{2602280}$ of each sample using Nanodrop followed by $0.8 \%$ Agarose gel electrophoresis using uncut $\lambda$ DNA as standard check and then dissolved in T10E1 buffer ( $\mathrm{pH} 8.0$ ) for storage and subsequent analysis.

Forty eight microsatellites (STMS and STS) markers were selected from the rice SSR linkage map (Temynkh et al. 2000, 2001; available online at http://www.gramene.org) based on the criteria: uniformity in distribution across the genome and high polymorphic information content. A total of 48 STMS markers were utilized of which only twelve (ten STMS and two STS, pTA248 and RM235 markers) were found polymorphic and utilized for molecular characterization of parents and respective hybrids. PCR reaction mixture (total volume of $25 \mu \mathrm{l}$ ) contained $1.5 \mu \mathrm{l}(20 \mathrm{ng})$ genomic DNA sample, $0.5 \mu \mathrm{l}\left(40 \mu\right.$ mole $\left.\mathrm{l}^{-1}\right)$ primers of forward and reverse sequences, $2.5 \mu \mathrm{l} 10 \mathrm{XPCR}$ buffer, $0.5 \mu \mathrm{l}$ dNTPs mix (10 m mole l-1), $1.5 \mu \mathrm{IgCl}_{2}\left(20 \mathrm{~m} \mathrm{~mole}^{-1}, 0.3 \mu \mathrm{l} \mathrm{Taq}\right.$ DNA polymerase ( $5 \mathrm{UL}^{-1}$, MBI Fermentas Hanover, USA) and $17.7 \mu$ double distilled water. The PCR reaction was performed in Thermal Cycler (Mastercycler gradient, Eppendorf, Hamburg, Germany) as initial DNA denaturation at $94^{\circ} \mathrm{C}$ for $5 \mathrm{~min}$ followed by $35-39$ cycles $\left(94^{\circ} \mathrm{C}\right.$ for $1 \mathrm{~min}, 55^{\circ} \mathrm{C}$ for $1 \mathrm{~min}, 72^{\circ} \mathrm{C} 1 \mathrm{~min}$ ) and final extension step at $72^{\circ} \mathrm{C}$ for $10 \mathrm{~min}$. The annealing temperature was modified by redesigning $(<\mathrm{GC} \%)$ the primers used for the study.

Amplified product was resolved in $3.0 \%$ Agarose gel in 0.5 X TAE buffer and stained with Ethidium bromide $\left(0.5 \mu \mathrm{g} \mathrm{ml}^{-1}\right)$ for visualization. DNA amplified product were mixed with loading dye in 5:1 ratio before loading the samples in the Agarose gel for electrophoresis in 0.5X TAE buffer. The electrophoresis was carried out for about 3 hrs at 80 volts. The molecular weight marker (50 bp ladder and $100 \mathrm{bp}$ ladder) were used to compare the molecular weights of amplified fragments. After electrophoresis, the gel was visualized under UV and photographed using Gel-Doc system (Alpha Innovation Technology Corporation, USA). Only clear-cut and unambiguous bands were scored and faint bands were omitted.

Statistical analysis : SSR and STS markers generated clear and unambiguous bands of various molecular weight sizes, were scored for absence (0) and presence (1) of the corresponding band among all the 22 genotypes (hybrids and parental lines) and a binary data matrix was prepared for further analysis using NTSYS-pc ver. 2.11W (Rohlf, 1997).

The SimQual programme was followed to calculate the Jaccard's similarity coefficients (Jaccard, 1908). The resulting similarity matrix was used for unweighted pair group method with arithmetic averages (UPGMA) based dendrogram (Sneath and Sokal, 1973) using the sequential agglomerative hierarchical nested cluster analysis (SAHN) module of NTSYSpc software.

The data generated from molecular markers banding pattern were also used for correlation coefficient analysis.

\section{Results and Discussion}

Molecular characterization of hybrids and their parental lines : Recent advancement in molecular techniques has opened the door through which specific molecular fingerprints of parental lines and hybrids that may serve the purpose, efficiently, can be developed (Yun et al., 2005; Antonova et al., 2006). In the beginning, PCR based RAPD marker was used for DNA fingerprinting of hybrids/ genotypes of rice (Wang et al., 1994), but after the developments of microsatellite markers (Mc Couch et al., 1997, 2002), STMS and STS, which are co-dominant in nature, has chromosomal specificity and can generate variety specific profiles with high fidelity and capable to differentiate between the homozygous and heterozygous genotypes (Yun et al., 2005; Antonova et al., 2006; Sundaram et al., 2008; Vikas et al., 2014). There are more than nineteen thousands of well distributed and mapped STMS and STS markers reported in the rice (Tamilkumar et al., 2009; Lea et al., 2010; Gramene, 2016), that have constituted a large group of markers for detecting polymorphism between parental lines of hybrids. A clear-cut identity and ensured genetic purity of seeds in hybrids/ varieties are important to protect the intellectual properties of developers (breeders) and also to the farmer's interest. 
Objectively, 48 STMS markers were taken from Gramene database (www.gramene.org) covering $67 \%$ genome of rice were used to survey the polymorphism between the hybrids and parental lines. The high polymorphic information content (PIC) of STMS had promoted for application as molecular markers for DNA finger printing (Ashikawa et al., 1999). Among 48 markers, 12 markers showed polymorphism (informative marker) which were further utilized for molecular characterization of parents/ hybrids and seed purity assessment of seed lots of respective hybrids and parental lines. The polymorphic survey in parental lines showed 108 heterozygous alleles with an average of nine alleles per marker. Amongst five markers, RM154, RM164, RM234, RM258 and RM519 were found to be most informative, amplifying the highest 13 heterotic alleles (hybrids and/or parental lines), and on contrary, marker RM 122 produced minimum number of alleles (2). Besides, RM19 showed highest PIC value (0.93) while RM154, RM519 and RM164 were shown least PIC (0.01) (Table 3). Out of 12 informative markers, 8 were (RM19, RM154, RM164, RM205, RM234, RM250, RM 258 and RM519) exhibited polymorphism and produced unique fingerprint throughout the parental lines and their hybrids. Five of these markers (RM154, RM164, RM234, RM258 and RM519) revealed heterozygosity over all hybrids and identified as reference markers for unambiguous identification (Figure 1). The STMS marker, RM 19 amplified alleles were specific to the parental lines of CNRH 3 and APHR 2. Similarly, two STMS marker RM 205, RM 250 and a STS marker pTA248 showed polymorphism in seven hybrids ,Pant Sankar Dhan-1, Pant Sankar Dhan 3, Narendra Sankar Dhan 2, KRH-2, CORH-2, Sahyadri and DRRH-1. However, these markers did not show polymorphism in hybrids $\mathrm{CNRH} 3$ and APHR 2 which might be due to the use of same CMS (IR 62829A) source in the development of these hybrids. Marker RM 203 was amplified in the parental lines (CMS lines, IR62829 and IR 58025, and respective maintainers) and failed to amplify in all the hybrids under study. These results are in close agreement with Yoshitola et al. (2002). Since STMS and STS markers cover whole genome, they show polymorphism in DNA banding pattern of different genotypes which reveal the variation and allelism (marker alleles) in larger quantity (Yashitola et al., 2002; Nandkumar et al., 2004; Sayyed et al., 2009; Antonova et al., 2006; Sundaram et al., 2008 ; Jaikishan et al., 2010; Pallavi et al., 2011 Kumar etal., 2012; Vikas et al., 2014; Kumar etal., 2016).

The variation in the PCR amplified product sizes in the parental lines revealed that marker RM154, RM234 and RM258 (Fig. 1.) had polymorphism in all nine hybrids and their parental lines amplified the band sizes of 140 to $270 \mathrm{bp}, 130$ to $270 \mathrm{bp}$ and 140 to $230 \mathrm{bp}$, respectively. Moreover, RM164 showed an average band size of $200 \mathrm{bp}$ and it ranged upto 140 to $240 \mathrm{bp}$ and RM519 showed band size of 130 to 200 bp over all the parental lines screened. RM250 and RM205 produced polymorphic pattern in parental lines of seven hybrids and produced band ranging from 120 to $200 \mathrm{bp}$. However, RM 19 showed polymorphic pattern only in parental lines of hybrids $\mathrm{CNRH} 3$ and
APHR 2 (both have common CMS source i.e., IR 62829A) and produced bands in the range of $150-200 \mathrm{bp}$. A STS marker pTA 248 showed polymorphism for all the hybrids and parental lines screened. The RM235 could not distinguish heterozygosity between parental lines of any hybrid in the PCR amplification. The markers RM 250 and pTA248 were found to be polymorphic for all the parental lines of hybrids except for CNRH 3 and APHR 2 (involved CMS, IR62829A as female), which suggests to use these markers for testing the genetic purity of hybrids developed utilizing CMS IR 58025A as the female parent. Though the STMS marker RM19 produced polymorphic pattern in parental lines of hybrids CNRH 3 and APHR 2, but failed to amplify in remaining seven hybrids in one PCR condition. There is possibility to obtain polymorphism between parental lines of hybrids with some modification in PCR conditions (Nandkumar et al., 2004; Jaikishan et al., 2010; Lea et al., 2010). It indicated large variation in the frequency of heterozygosity in all hybrids tested, which ranged from $6 \%$ to $70 \%$ for STMS loci and 0 to $50 \%$ for STS loci. Of the 12 informative markers used, 5 markers were identified to detect the polymorphism in all the parental lines and nine hybrids. Thus, it seems that these 5 markers can be widely employed for identification of these hybrids and their parental lines.

DNA profiling and genetic purity assessment : Genetic adulteration in hybrid seeds caused drastic reduction in heterosis expression was studied by molecular markers in indica rice hybrids (Mao et al., 1998; Yun et al., 2005). In hybrid breeding programme, maintenance of genetic putity in parental lines is most important feature for the development of pure/ true hybrid seeds. Though grow out test is one of the conventional and standard techniques commonly used for the assessment of genetic purity of seeds, it is not that much popular due to its limitations, especially time consuming process. The recent molecular technologies for genetic purity assessment are rapid, robust and reliable (Yashitola et al., 2002). The assessments of heterozygosity of parental lines and hybrids were undertaken using five hybrid specific STMS markers viz., RM154, RM164, RM234, RM258 and RM519, which were identified through polymorphism survey. Fifty seeds from each parental lines were subjected to draw the fingerprinting based on STMS markers. It was found that only one parental line IR 62829A showed one heterozygote for all the markers tested, while their B-line of same CMS and restorer lines did not detect any heterozygote bands using all five markers. Further analysis showing heterozygote bands confirm the impurities of $4 \%$ in seed lots of IR 62829A CMS lines.

Assessment of genetic purity of hybrids (10 hybrids, included one more hybrid seed lot of Pant Sankar Dhan 1 produced and marketed by M/S Syngenta India Ltd.) by application of molecular markers (five STMS) were carried out on 50 randomly selected seeds from seed lot of each hybrid. Genetic purity analysis indicated the maximum number of offtype plants in hybrid seed lot of Narendra Sankar Dhan 2 (6 plants) (Fig. 2) followed by CNRH 3 (4 plants) and Pant Sankar 


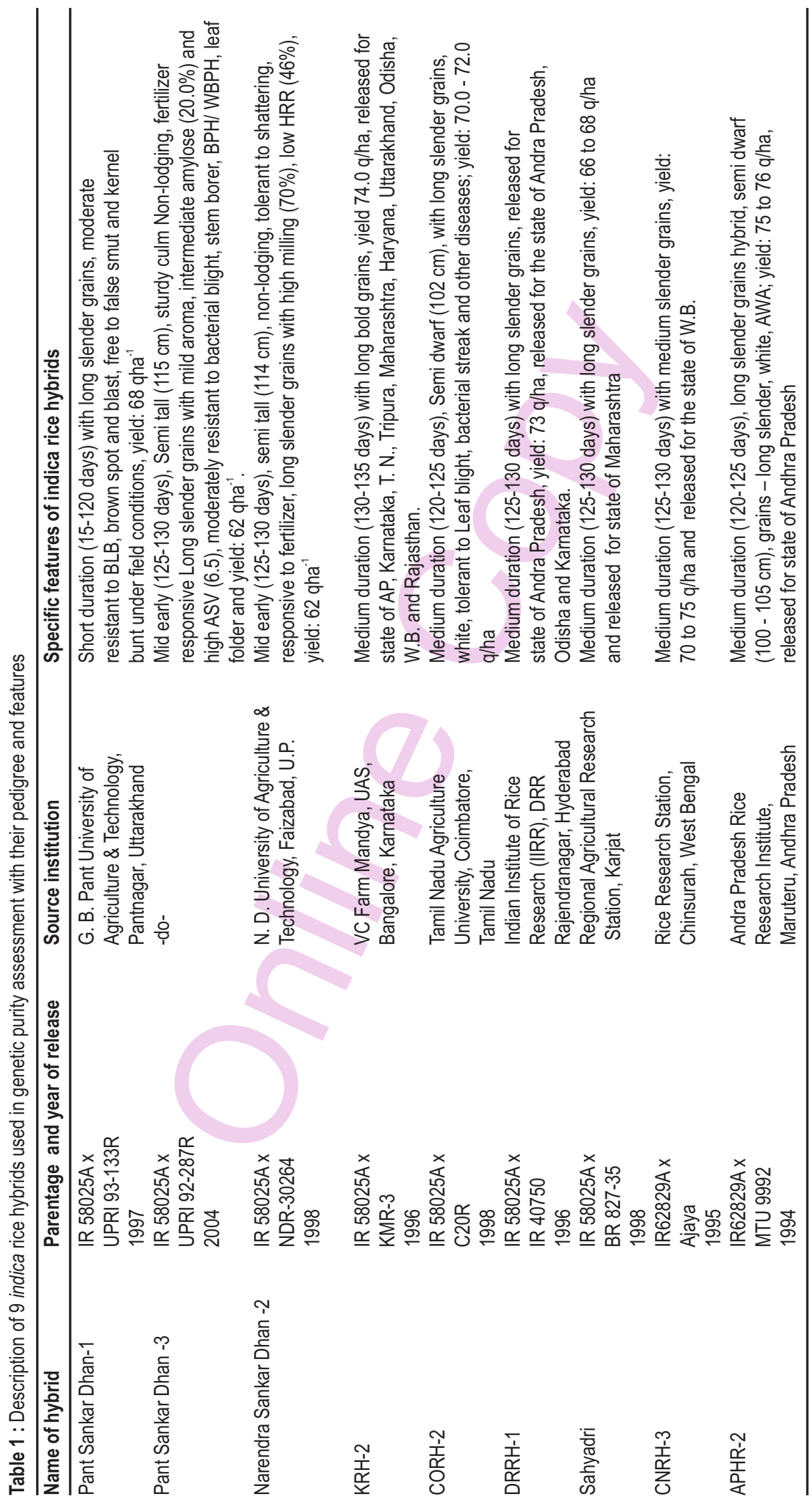


Table 2 : List of microsatellites/STS markers used in screening of hybrid and parental lines

\begin{tabular}{|c|c|c|c|c|}
\hline S.No. & Markers & Chromosome number & Motif \& No. of repeat & Size range (bp) \\
\hline 1 & RM12233 & 1 & $(A G G) 8$ & 83 \\
\hline 2 & RM173 & 1 & $\{(\mathrm{GT}) 3 \mathrm{~T} 2 \mathrm{AGGGACA}\} 2$ & 173 \\
\hline 3 & RM220 & 1 & (CT)17 & 127 \\
\hline 4 & RM10746 & 1 & $(A G) 10$ & 173 \\
\hline 5 & RM203 & 2 & (AT)21 & 203 \\
\hline 6 & RM154 (OSR11) & 2 & (GA)21 & 183 \\
\hline 7 & RM250 (RM14024) & 2 & (CT)17 & 153 \\
\hline 8 & RM263 & 2 & (CT)34 & 199 \\
\hline 9 & RM 15981 & 3 & (AG)46 & 259 \\
\hline 10 & RM 14811 & 3 & (AG)19 & 332 \\
\hline 11 & RM1510 & 3 & $(\mathrm{CCG}) 7$ & 183 \\
\hline 12 & RM15621 & 3 & $(A G) 12$ & 282 \\
\hline 13 & RM19 & 4 & (ATC) 10 & 226 \\
\hline 14 & RM16284 & 4 & $(A G) 15$ & 292 \\
\hline 15 & RM16336 & 4 & (AGAT)5 & 569 \\
\hline 16 & RM16762 & 4 & $(\mathrm{CCG}) 7$ & 100 \\
\hline 17 & RM 18336 & 5 & (AT)34 & 256 \\
\hline 18 & RM18004 & 5 & $(A A G) 15$ & 189 \\
\hline 19 & RM164 (RM18617) & 5 & (GT)16 & 246 \\
\hline 20 & RM122 & 5 & (GA)11 & 227 \\
\hline 21 & RM 20522 & 6 & (AG)23 & 122 \\
\hline 22 & RM 19456 & 6 & (AAT)20 & 183 \\
\hline 23 & RM19546 & 6 & $(A A G) 7$ & 394 \\
\hline 24 & RM20512 & 6 & $(A G) 14$ & 236 \\
\hline 25 & RM 21395 & 7 & (AG)13 & 90 \\
\hline 26 & RM 21427 & 7 & $(A A G) 8$ & 189 \\
\hline 27 & RM 20810 & 7 & (AT)34 & 197 \\
\hline 28 & RM234 (RM21972) & 7 & (CT)25 & 156 \\
\hline 29 & RM23107 & 8 & $(A G) 14$ & 96 \\
\hline 30 & RM22230 & 8 & $(A G) 34$ & 291 \\
\hline 31 & RM23528 & 8 & $(A G G) 8$ & 104 \\
\hline 32 & RM 22914 & 8 & (AG)29 & 0 \\
\hline 33 & RM24412 & 9 & $(A G) 11$ & 290 \\
\hline 34 & RM2456 0 & 9 & (GCG)7 & 420 \\
\hline 35 & RM205 & 9 & (CT)25 & 122 \\
\hline 36 & RM201 & 9 & (CT)17 & 158 \\
\hline 37 & RM228 & 10 & (CA)6(GA)36 & 154 \\
\hline 38 & RM258 (RM25600) & 10 & (GA)21 & 148 \\
\hline 39 & $\mathrm{RM} 216$ & 10 & (CT)18 & 146 \\
\hline 40 & RM171 & 10 & (GATG)5 & 328 \\
\hline 41 & RM27235 & 11 & (AC)12 & 266 \\
\hline 42 & RM224 & 11 & $(\mathrm{AAG}) 7$ & 20 \\
\hline 43 & pTA 248 & 11 & - & 750 \\
\hline 44 & RM206 & 11 & (CT)21 & 147 \\
\hline 45 & RM27644 & 12 & $(A G) 11$ & 278 \\
\hline 46 & RM519 (RM28302) & 12 & $(A A G) 8$ & 122 \\
\hline 47 & RG235 & 12 & (CT)24 & 124 \\
\hline 48 & RM247 & 12 & (CT)34 & 199 \\
\hline
\end{tabular}

Dhan 1 (2 plants). Hybrids DRRH 1, COHR 2 and APHR 2 showed 3 off-type plants each in their seed lots, while seed lots of hybrid Pant Sankar Dhan 3 and Sahyadri indicated much greater genetic purity with only single off-type plant.

Genetic similarity/dissimilarity among hybrids and parental lines : Genetic diversity among parents is key determinant to predict the level of heterosis in hybrid well advance. Purposely, a total of 12 informative microsatellite markers revealed varying degree of genetic relatedness among nine indica rice hybrids and their 13 parental lines (22 genotypes) were taken to assess the genetic diversity among hybris/lines. Since Jaccard's similarity coefficient ranged from 0.77 to 0.99 , a wide variation was observed between and among 22 genotypes due to diversified 


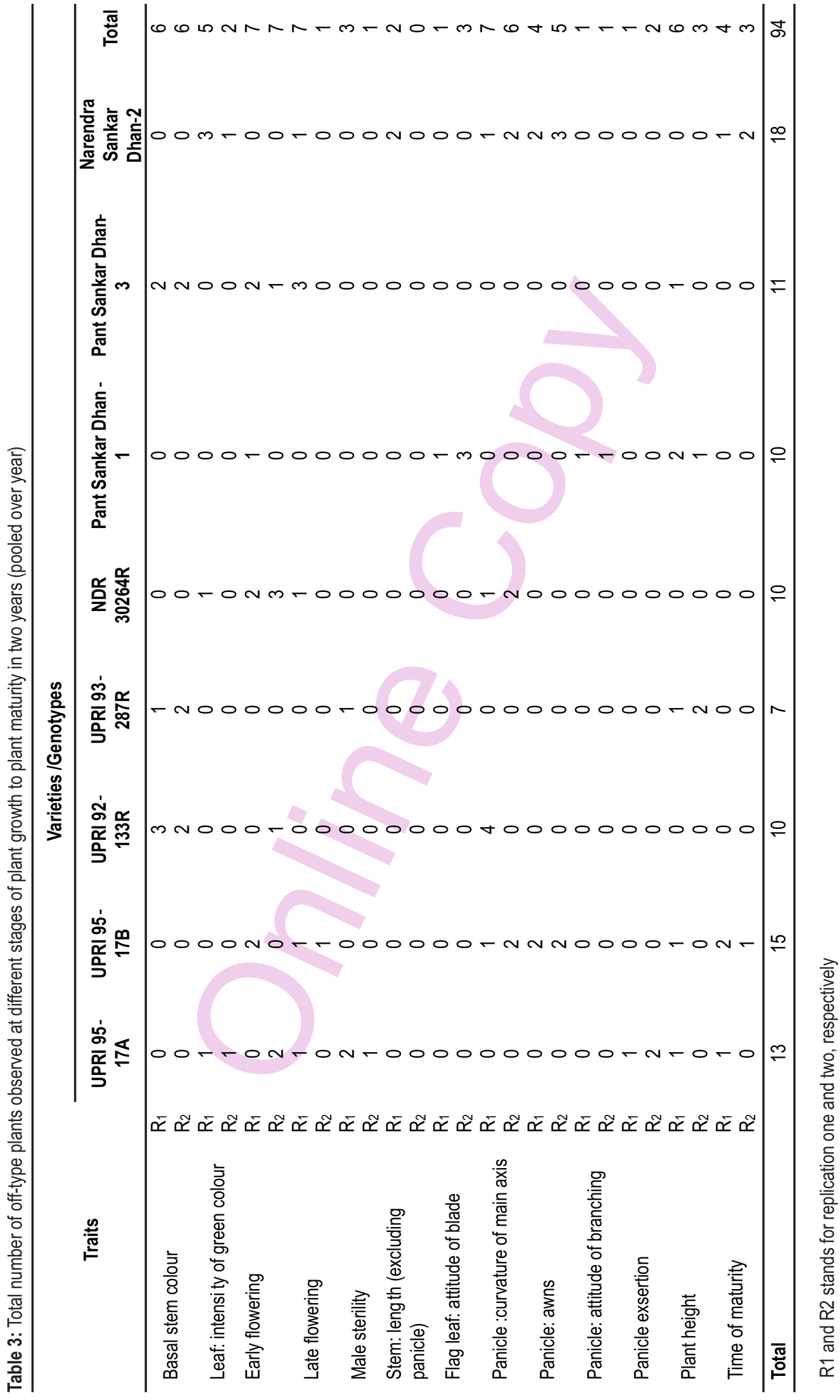


morphology and variation among the rice genotypes (Fig. 3). These informative markers were grouped nine hybrids in two clusters viz., first group had 7 hybrids and second group had 2 hybrids (CNHR3 and APHR2) (Fig. 4). However, 13 parental lines were grouped in two main clusters and five sub-categories based on genetic similarities. High genetic similarity coefficient (0.99) was found between five pairs of genotypes viz., restorer line NDR30264R and IR40705R, sterile and maintainer line IR62829A and IR62829B, hybrids CNHR3 and APHR2, Pant Shankar Dhan1 and KRH2. Whereas, least genetic similarity was observed 0.77 between 10 pairs of genotypes viz., MTU9992 and IR58025B, Ajaya and NDR30264R, APHR2 and KRH2, CNHR3 and $\mathrm{COHR} 2$, Ajaya and KMR3 etc.

The UPGMA Dendogram of 22 rice genotypes including nine hybrids were grouped into two main clusters consisting of 18 and 4 genotypes, respectively (Fig. 3). Cluster I was further divided into five sub-clusters i.e., sub-cluster la (two genotypes: IR62829A and IR62829B), Ib (seven genotypes/ hybrids: PSD1, PSD3, NSD2, KRH2, COHR2, DRRH1 and Sahyadri), Ic (UPRI93-133R, UPRI93-287R, KMR3, C20R and BR827-35) and Id consisted of two genotypes IR58025A and IR58025B. However, cluster /I was also divided into two sub-clusters, subcluster Ila and IIb, each consisted only two genotypes viz., Ajaya and MTU9992; CNHR3 and APHR2, respectively. Clustering pattern of parental line showed substantial genetic distance between parents which in fact led the level of heterosis in studied hybrids. Similar finding was observed in recent past by Rajendran et al. (2012) who reported two major clusters of the maintainer and restorer groups with sub-clusters in each group and overall genetic similarity index value ranging from 0.69 to 0.87 with mean value of 0.78 .

Grow out test : The most important quality characteristic of a hybrid is its reliability or purity. In scientific seed production programme, inspite of intense care to maintain the parental lines as well as hybrids purity some extent of impurity may occur due to improper flowering isolation and varietal admixtures. Grow out test has been used as one of the standard conventional approach to determine the true-to-type seeds of parental lines and their hybrids (Sonti et al., 2003; Garg et al., 2006). In this study, genetic purity of 8 genotypes (3 hybrids, Pant Sankar Dhan1, Pant Sankar Dhan 3 and Narendra Sankar Dhan 2; and 5 parental lines) from 4 seed lots of hybrids was assessed through conventional approach, grow out test. A total of 94 off-type/ mixture plants were found under field evaluation. Highest number of off-type plants was found in hybrids Narendra Sankar Dhan-2 (18 plants) followed by Pant Sankar Dhan 3 (11 plants) and lowest in hybrid Pant Sankar Dhan 1 (10 plants) (Table 3).

In parental lines, UPRI 95-17B exhibited maximum number of off-type plants (15 plants) followed by UPRI 95-17A(13 plants) and UPRI 92-133R and NDR 30264R (10 plants in each).

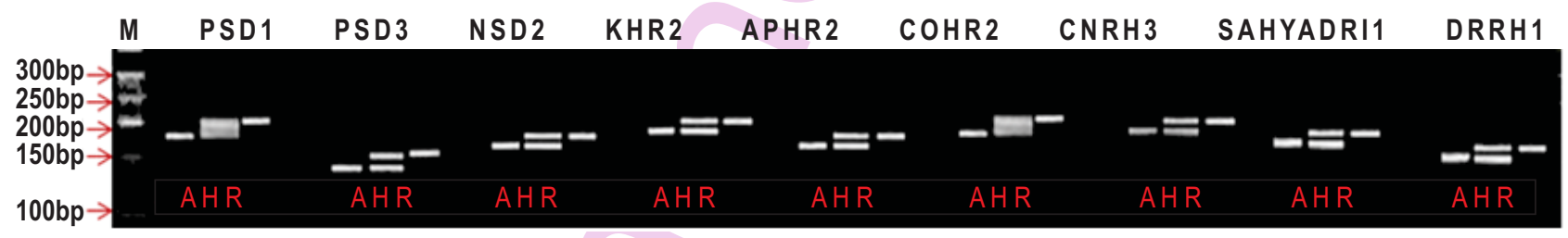

Fig. 1: The molecular profiles obtained by STMS marker RM 258 of 9 indica rice hybrids with respective parents (Aand $R$ lines). $M=50 \mathrm{bp}$ ladder, $A=C M S$ line (Aline), $\mathrm{H}=$ hybrid ( $\mathrm{F}_{1}$ hybrids), $\mathrm{R}=$ restorer line (Rline)

AR 1234567891011121314151617181920212223242526272829303132333435363738394041424344454647484950

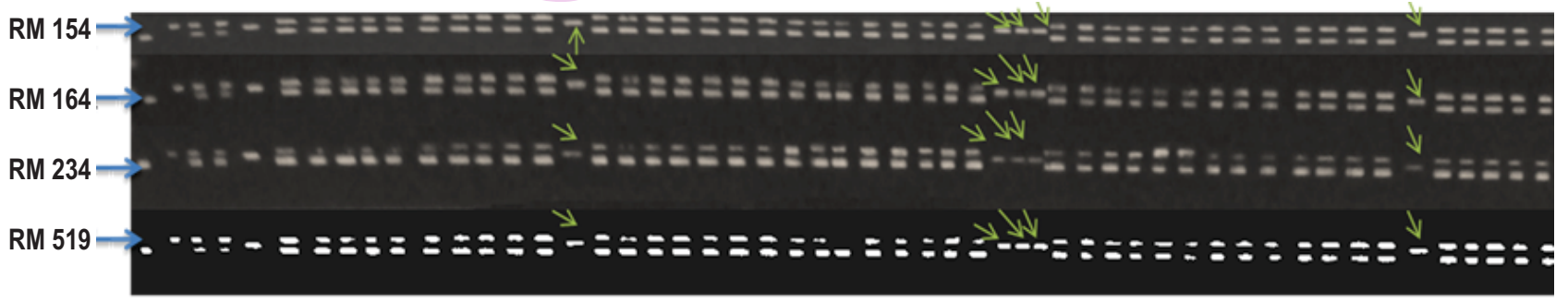

Fig. 2: STMS markers (RM154, RM164, RM234 and RM519) based genetic purity (mixture seed) assessment of hybrid Narendra Sankar Dhan-2 (NSD2) with their parental line. Band size varies approximately 150 to 260 bp. Lane 1= IR 58025A, Lane 2= ND 30264R and lane 3-51 represents individual F1 hybrid plants taken by random sampling from hybrid seed lot of NSD 2. Arrow represents in sample 14, 30,31, 32 and 46 showed mixture/ off-type plants in hybrids 


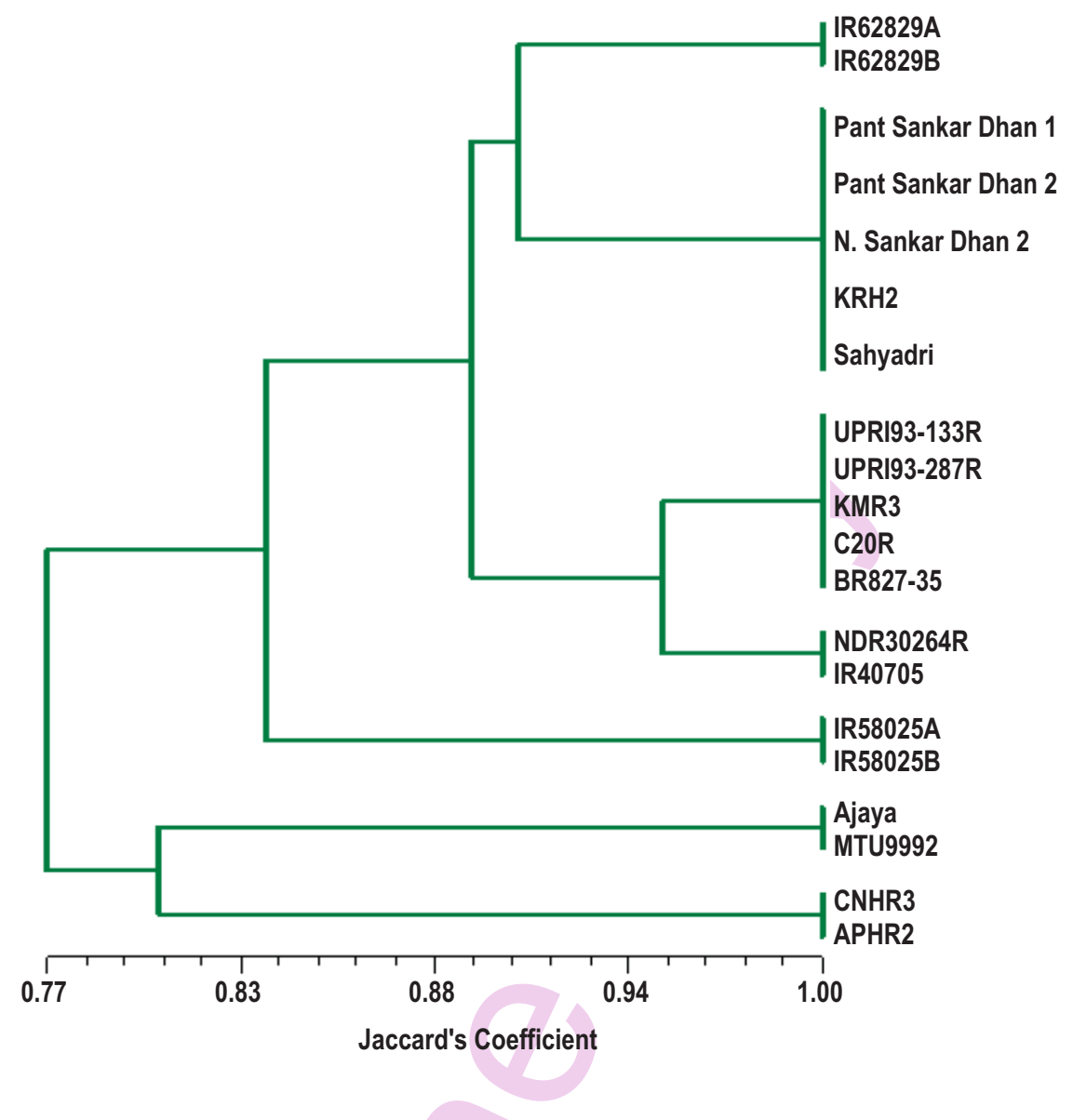

Fig. 3 : Dendogram of 22 rice genotypes including 9 hybrids based on Jaccard's similarity coefficients based on 12 informative STMS markers

The lowest number of off-type plants were recorded in UPRI 93287R (7 plants). Morphological characterization of genotypes showed maximum number of off-type plants with reference to certain traits i.e., early flowering, panicle curvature of main axis, basal stem colour and plant height. The off-type plant were observed for early flowering, followed by panicle curvature of main axis, basal stem colour and plant height is 14, 13, 12 and 9 plants, respectively. However, the lowest numbers of off-type plants were observed in case of stem length (excluding panicle) and attitude of panicle branching with two plants. In grow out test, the tested parental lines and hybrids indicated the maximum percentage of off-type plants in hybrid Narendra Sankar Dhan-2 $(19 \%)$ and lowest in UPRI 93-287R (7.44\%). Further, off-type plants were differentiated on the basis of their traits where highest off-type plants were observed with respect to early flowering, late flowering and panicle curvature of main axis ( $7.44 \%$ for each) and minimum of $1.06 \%$ for the stem length (excluding panicle). Thus, statistical analysis of grow out test revealed $88.25 \%$ genetic purity in three hybrids tested. Though, grow out test is used as a standard conventional approach in differentiation of hybrids, however, there are some limitations like more time consuming and inconvenient process of screening of genotypes (Kumar et al., 2012).
Efficacy of molecular marker and grow-out test : Four seed lots of three hybrids Pant Sankar Dhan 1, Pant Sankar Dhan 3 and Narendra Sankar Dhan 2 were utilized for correlation coefficient analysis between off-type plants in seed lots of hybrids through grow out test and molecular marker based DNA fingerprinting analysis. The results showed highly significant positive association ( $r=0.96)$ between grow out test and molecular marker based fingerprinting for genetic purity assessment of hybrids and parental lines (Kumar et al., 2012; Vishwanath et al., 2012). Thus, the results of molecular markers based fingerprinting in the laboratory can be used as a substitute for grow-out test. Markers identified in the present study can be utilized for genetic purity testing of the hybrids. The STMS marker information developed through this study will certainly be of enormous help for hybrid rice seed industry to select appropriate marker combinations and assess genetic purity of the parental lines of hybrids.

Hence, genotype specific STMS markers identified in the study and their close association with the ability of "grow-out test", emphasizes immense scope for molecular approaches to be an alternatives in unambiguous assessment of genetic purity of 
hybrids and their parents seed. The markers identified may be useful as reference markers in future breeding programme and seed production programme for identification and protection of these nine hybrids from mixture of other variety seeds. The molecular markers based genetic purity assessment can be an effective, rapid and robust technique for the assessment of genetic purity of hybrids and would have great benefit to the farmers and agencies involved in this venture, hybrid rice seed production and cultivation.

\section{Acknowledgments}

Authors (RLV) are highly grateful to the Indian Council of Agricultural Research, New Delhi, India for providing the fellowship grant as senior research fellowship during Ph.D. degree programme.

\section{References}

Antonova, T.S., S.Z. Guchetl, T.A. Tchelustnikova and S.A. Ramasanova: Development of marker system for identification and certification of rice lines and hybrids on the basis of SSR analysis. Helia, 29, 63-72 (2006).

Ashikawa, I., N. Kurata, S. Saji, Y. Umehara and T. Sasaki: Application of restriction fragment fingerprinting with a rice microsatellite sequence to assembling rice YAC clones. Genome, 42, 330-337 (1999).

Bora, A., P.R. Choudhury, V. Pande and A.B. Mandal: Assessment of genetic purity in rice (Oryza sativa L.) hybrids using microsatellite markers. 3 Biotech., 6(1): 50. doi: 10.1007/s13205-015-0337-y (2016).

Dash, A.K., R.N. Rao, G.J.N. Rao, R.L. Verma, J.L. Katara, A.K. Mukherjee, O.N. Singh and T.B. Bagchi : Phenotypic and MarkerAssisted Genetic Enhancement of Parental Lines of Rajalaxmi, an Elite Rice Hybrid. Front. Plant Sci. 7:1005. doi: 10.3389/fpls.2016.01005(2016)

Garg, A., A.K. Singh, K.V. Prabhu, T. Mohapatra, N.K. Tyagi, N. Nandakumar, R. Singh and F.U. Zaman: Utility of a fertility restorer gene linked marker for testing genetic purity of hybrid seeds in rice (Oryza sativa L.). Seed Sci. Tech., 34, 9-18 (2006).

Gramene: Gramene database of rice, retrieved from url: "http://www.gramene.org" (2016).

IRRI: Production database at International Rice Research Institute, Manila, Philippines. www.irri.org/production/2015/html (2015).

Jaccard, P.: Nouvelle srecherches sur la distribution florale. Bull. Soc. Vaud. Sci. Nat., 44, 223-270 (1908).

Jaikishan, I., P. Rajendrakumar, M.S. Ramesha, B.C. Viraktamath, S.M. Balachandran, C.N. Neeraja, K. Sujatha, K. Rao, P. Natarajkumar, Y. Hari, K. Sakthivel, A.S. Ramaprasad and R.M. Sundaram: Prediction of heterosis for grain yield in rice using 'key' informative EST-SSR markers. PlantBreed., 129, 108-111 (2010).

Kumar, M.R.C., K. Visshwanath, N. Shivakumar, P.S. Rajendra, B.N. Radha and Ramegowda: Utilization of SSR markers for seed purity testing in popular rice hybrids (Oryza sativa L.). Annals Plant Sci., 1, 1-5 (2012).

Kumar, S., V. Kumar, P. Kumari, Kirti, A.K. Singh and R. Singh : DNA fingerprinting and genetic diversity studies in wheat genotypes using SSR markers. J. Environ. Biol., 37, 319-326, (2016).
Lea, A.A., C.A. Mangolin, A.T. Amaral, L.S.A. Gonçalves, C.A. Scapim, A.S. Mott, I.B.O. Eloi, V. Cordoves and M.F.P. Silva: Efficiency of RAPD versus SSR markers for determining genetic diversity among popcorn lines. Genet. Mol. Res. 9, 9-18 (2010).

Lu, Y., C. Lan, S. Liang, X. Zhou, D. Liu, G. Zhou, Q. Lu, J. Jing, M. Wang, $X$. Xia and Z. He: QTL mapping for adult plant resistance to tripe rust in Italian common wheat cultivars Libellula and Strampelli. Theor. Appl. Genet., 119, 1349-1359 (2009).

Mao, C.X., S.S. Virmani and I. Kumar: Technology innovation to lower the cast of hybrid seed production. In : Advances in Hybrid Rice Technology. Proceeding of Third International Symposium on Hybrid Rice, pp. 111-128 (1998).

McCouch, S.R., L. Teytelman, Y. Xu, K.B. Lobos, K. Clare, M. Walton, B. $\mathrm{Fu}, \mathrm{R}$. Maghirang, Z. Li and Y. Xing: Development and mapping of 2240 new SSR markers for rice (Oryza sativa L.). DNA Res., 9 , 199-207 (2002).

McCouch, S.R., X. Chen, O. Panaud, S. Temnykh and Y. Xu: Microsatellite marker development, mapping and applications in rice genetics and breeding. Plant Mol. Biol., 35, 89-99 (1997).

Murray, M.G. and W.F. Thompson: Rapid isolation of high molecular weight plantDNA. Nucleic Acids Res., 8, 4321-4326 (1980).

Nandakumar, N., A.K. Singh, R.K. Sharma, T. Mohapatra, K.V. Prabhu and F.U. Zaman: Molecular fingerprinting of hybrids and assessment of genetic purity of hybrid seeds in rice using microsatellite markers. Euphytica, 136, 257-264 (2004).

Pallavi, H.M., R. Gowda, Y.G. Shadakshari, K. Bhanuprakash and K. Vishwanath : Identification of SSR markers for hybridity and seed genetic purity testing in sunflower (Helianthus annuus L.) Helia, 34, 59-66 (2011).

Rajendran, N., L. Mukherjee, K.K. Reddy and H.E. Shashidhar: DNA fingerprinting and estimation of genetic diversity among hybrid rice parental lines (Oryza sativa L.) using simple sequence repeats (SSR) markers. J. Plant Breeding Crop Sci., 4, 169-174 (2012).

Rehem, B.C., A.A.T. Almeida, R.X. Correa, A.S. Gesteira, M.M. Yamada and R.R. Valle: Genetic mapping of Theobroma cacao (Malbaceae) seedlings of the Parinari series, carriers of the lethal gene Luteus-Pa. Genet. Mol. Res., 9, 1775-1784 (2010).

RMM-USDA-2015 : FAO, Rice Market Monitor, http://www.fao.org/ economic/est/ publications/rice-publications/rice-market-monitor$\mathrm{rmm} / \mathrm{en}$, retrieved on 10 July, 2015, (2015).

Rohlf, F.J.: NTSYS-pc (Numerical taxonomy and multivariate analysis system), version 2.02i, Exeter, Setauket, New York, USA, (1997).

Sasaki, T. : The map-based sequence of the rice genome. Nature, 436, 793-800 (2005).

Sayyed, H.H., A.M.M. Sayyed, A.N. Ghorban and A. Ahmad: Identification of rice hybrids using microsatellite and RAPD markers. African J. Biotechnol., 8, 2094-2101 (2009).

Singh, M.K., P. Singh, R.P. Singh and C. Mohapatra: Association analysis for yield and quality attributes in Indica rice and screening of hybrids against blast disease (Magnaporthe grise Barr.). J. Plant Sci., DOI:10.3923/jps.2013(2013).

Singh, P., R.P. Singh, H.B. Singh, O.N. Singh, S. Samantray, M.K. Singh and H.K. Jaiswal: Inheritance of bacterial leaf blight (Xanthomonas oryzae pv. oryzae) resistance in Indica rice cultivar HUR 4-3. Int. J. Agric. Environ. Biotech., 9, 255-263 (2014).

Sneath, P.H.A. and R.R. Sokal: Numerical taxonomy. Freeman, San Francisco, USA (1973).

Sonti, R.V., J. Yashitola, T. Thirumurugan, R.M. Sundaram, M.S. Ramesha and N.P. Sharma: DNA markers to assess genetic purity of rice hybrids. Adv. in Rice Genetics, Los Banos, Laguna, Philippines, pp. 223-225 (2003). 
Sundaram, R.M., Naveenkumar, B.S.K. Biradar, S.M. Balachandran, B. Mishra, A.M. Ilyas, B.C. Viraktamath, M.S. Ramesha and N.P. Sharma: Identification of informative SSR markers capable of distinguishing hybrid rice parental lines and their utilization in seed purity assessment. Euphytica, 163, 215-224 (2008).

Tamilkumar, P., R. Jerlin, N. Senthil, K.N. Ganesan, R.J. Jeevan and M. Raveendran: Fingerprinting of rice hybrids and their parental lines using microsatellite markers and their utilization in genetic purity assessment of hybrid rice. Res. J. Seed Sci., 2, 40-47 (2009).

Temnykh, S., W.D. Park, N. Ayres, S. Cartinhour, N. Hauck, L. Lipvich, Y.G. Cho, T. Ishi and S.R. McCouch : Mapping and genome organization of microsatellite sequences in rice (Oryza sativa L.). Theor. Appl. Genet, 100,697-712 (2000).

Temnykh, S., G. DeClerck, A. Lukashova, L. Lipovich, S. Cartinhour and S.R. McCouch : Computational and experimental analysis of microsatellites in rice (Oryza sativa L.): Frequency, length variation, transposon associations, and genetic marker potential. Genome Res., 11, 1441-1452 (2001).

Vikas, P., S.K. Verma, M.S. Xalxo, R.R. Saxena, N. Mehta and S.B. Verulkar: Identification of microsatellite markers for fingerprinting popular Indian flax (Linum usitatissimum L.) cultivars and their utilization in seed genetic purity assessments. Aus. J. Crop Sci., 8, 119-126 (2014).

Virmani, S.S.: In: Heterosis and Hybrid Rice Breeding. Monographs on Theoretical and Applied Genetics, IRRI, pp. 79-106 (1994).

Vishwanath, K., C. Kumar, N. Shivakumar, P.S. Rajendra, B.N. Radha and Ramegowda: Utilization of SSR markers for seed purity testing in popular rice hybrids (Oryza sativa L.). Annals Plant Sci., 1,1-5(2012).

Wang, G., S. Castiglione, J. Zhang, R. Fu, J. Ma, W. Li, Y. Sun and F. Sala: Hybrid rice (Oryza sativa L): Identification and parentage determination by RAPD fingerprinting. Plant Cell Rep., 14, 112-115(1994).

Yashitola, J., Thirumurugan, R.M. Sundaram, M.K. Naseerullah, M.S. Ramesha, N.P. Sharma and V.S. Ramesh: Assessment of purity of rice hybrids using microsatellite and STS markers. Crop Sci., 42, 1369-1373 (2002).

Yifru, T., K. Hammer, X.Q. Huang and M.S. Roder: Regional patterns of microsatellite diversity in Ethiopian tetraploid wheat accessions. Plant Breeding, 125, 125-130 (2006).

Yun, X.Y., Z. Zhang, X. Yi-Ping and Y. Long-ping: Identification and purity test of super hybrid rice with SSR molecular markers. Rice Sci., 12, 7-12(2005). 